\title{
OPEN Author Correction: Collagen XXV promotes myoblast fusion during myogenic differentiation and muscle formation
}

Tristan J. M. Gonçalves, Florence Boutillon, Suzie Lefebvre, Vincent Goffin, Takeshi Iwatsubo, Tomoko Wakabayashi, Franck Oury \& Anne-Sophie Armand

Correction to: Scientific Reports https://doi.org/10.1038/s41598-019-42296-6, published online 10 April 2019

In the original version of this Article, Takeshi Iwatsubo was incorrectly affiliated with both 'Department of Neuropathology, Graduate School of Medicine, the University of Tokyo, Tokyo, 113-0033, Japan' and 'Department of Innovative Dementia Prevention, Graduate School of Medicine, the University of Tokyo, Tokyo, 113-0033, Japan' The correct affiliation is listed below.

Department of Neuropathology, Graduate School of Medicine, the University of Tokyo, Tokyo, 113-0033, Japan.

In addition, Tomoko Wakabayashi was only affiliated with 'Department of Neuropathology, Graduate School of Medicine, the University of Tokyo, Tokyo, 113-0033, Japan'. The correct affiliations are listed below.

Department of Neuropathology, Graduate School of Medicine, the University of Tokyo, Tokyo, 113-0033, Japan.

Department of Innovative Dementia Prevention, Graduate School of Medicine, the University of Tokyo, Tokyo, 113-0033, Japan.

These errors have now been corrected in the HTML and PDF versions of this Article.

(c) (i) Open Access This article is licensed under a Creative Commons Attribution 4.0 International License, which permits use, sharing, adaptation, distribution and reproduction in any medium or format, as long as you give appropriate credit to the original author(s) and the source, provide a link to the Creative Commons license, and indicate if changes were made. The images or other third party material in this article are included in the article's Creative Commons license, unless indicated otherwise in a credit line to the material. If material is not included in the article's Creative Commons license and your intended use is not permitted by statutory regulation or exceeds the permitted use, you will need to obtain permission directly from the copyright holder. To view a copy of this license, visit http://creativecommons.org/licenses/by/4.0/.

(C) The Author(s) 2019 